\title{
DRIVERS FOR SELECTING THE TYPE OF TRANSPORT IN THE MOdAl SHIFT: COST, TRANSIT TIME AND ENVIRONMENTAL IMPACT ANALYSIS
}

\author{
Antonio Maria Coruzzolo ${ }^{1}$, Francesco Lolli ${ }^{1,2}$, Fabio Gennari ${ }^{1}$, \\ Samuele Marinello ${ }^{2 *} \&$ Rita Gamberini ${ }^{1,2}$ \\ ${ }^{1}$ Department of Sciences and Methods for Engineering, University of Modena and Reggio Emilia, \\ Via Amendola 2, Padiglione Morselli, 42122 Reggio Emilia, Italy \\ ${ }^{2}$ En\&Tech Interdepartmental Center of the University of Modena and Reggio Emilia, \\ Piazzale Europa 1, 42124 Reggio Emilia, Italy, * Corresponding author
}
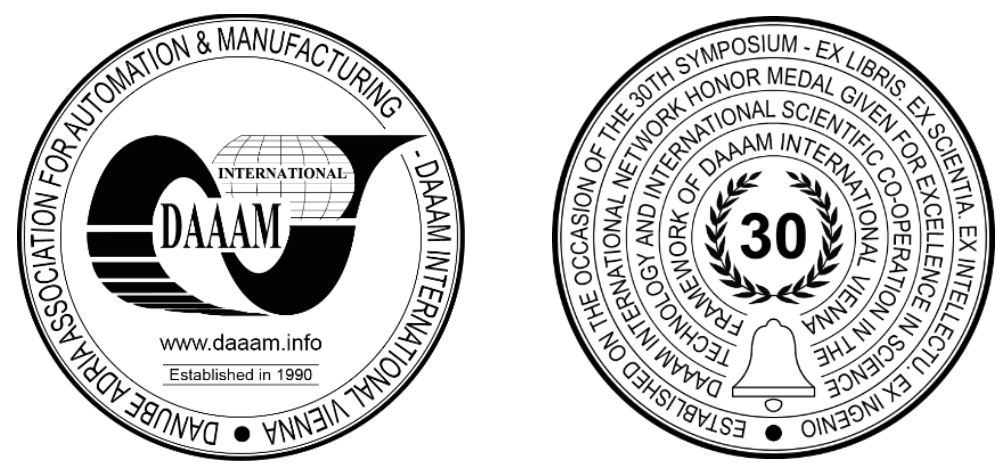

This Publication has to be referred as: Coruzzolo, A[ntonio] M[aria]; Lolli, F[rancesco]; Gennari, F[abio]; Marinello, S[amuele] \& Gamberini, R[ita] (2021). Drivers for Selecting the Type of Transport in the Modal Shift: Cost, Transit Time and Environmental Impact Analysis, Proceedings of the 32nd DAAAM International Symposium, pp.0423-0432, B. Katalinic (Ed.), Published by DAAAM International, ISBN 978-3-902734-33-4, ISSN 1726-9679, Vienna, Austria DOI: $10.2507 / 32$ nd.daaam.proceedings.062

\begin{abstract}
An increasing freight demand is putting pressure on the freight transport network, forced to pay high costs to ensure compliance with the conditions and delivery times, as well as to grow towards environmental sustainability. The purpose of this paper is to analyse the main drivers for choosing the type of transport in the planning of distribution logistics through the application of the Multinomial Logit Model (MLN) under the objective of $\mathrm{CO}_{2}$ emission minimisation in order to identify the most sustainable transport solution as a function of distance along the same lines as Hoover's diagrams. The approach has been applied to a real case study (the logistics department of an Italian manufacturing company) in order to define the mode of transport that minimises the quantity of carbon dioxide emitted and therefore to analyse the effect that this modal shift strategy has on the other selection drivers. The results were encouraging in guiding the application of a modal shift strategy and the change to more sustainable transport modes: $62.5 \%$ of the company's transport shipments should be transferred from road to a different mode, with an overall reduction of $41 \%$ of $\mathrm{CO}_{2}$ emissions, without any impact on costs and delivery time.
\end{abstract}

Keywords: Distribution logistics; Logit model; Multi-criteria; Optimisation; Sustainability

\section{Introduction and state of the art}

Nowadays an increasing freight demand is putting pressure on the freight transport network. Since most of this transport is based on fossil fuels, the change towards an efficient and sustainable freight transport system can no longer be postponed. In 2017 global primary energy consumption reached 9718 Mtoe (million tons of oil equivalent), among which the transportation sector accounted for $27.9 \%$ [1]. In addition to this high energy consumption, transportation contributes about $66 \%$ of the logistics cost [2]. 
Usually, the transportation of goods is carried out with different transportation modes: road, rail, air, sea. The combination of two or more modes of transportation with the same mobile storage unit is called intermodal [3]. It has been demonstrated that intermodal transport can reduce emissions. For example, intermodal transport comprising rail and road is $77.4 \%$ less polluting than full road transport [4]. For this reason, the development of a model that accounts also for the environmental impact as a selection driver for the modal shift is needed. In the literature, the environmental impacts are widely neglected by studies unless the study has a specific focus on the environment, as demonstrated in an empirical literature review on transportation buyers' choices [5], which highlighted clearly that the main driver considered is undoubtedly cost. This is the gap we want to fill, by providing an analysis of the main drivers for mode choices that also involve the environmental impact that can be useful for practitioners.

The problem of choosing different transportation modes, called the mode choice problem, is usually solved using the split model [6] in its disaggregate form. It relies on the utility theory [7] and presupposes that the option chosen by an individual is based on the characteristics of that individual and on the attributes of the option. The first application of this theory in the transportation sector was in 1985, by Ben-Akiva and Lerman [8] on transport demand. Since then, various extensions and applications can be found in the literature, and it is still in progress in the related literature. Della Chiara et al. [9] exploited a logit model as a split model, one of the most diffuse, to assess the influence of a ro-ro service between Italy and France, including the service frequency and total shipment time as drivers. Sivakumar et al. [10] used a fractional split model to estimate the fraction of the commodity consumed at each destination zone. Ferrari [11] extended the basic model in a dynamic way that supposes that the evolution over time of transport demand is coupled with a corresponding evolution of transport modes, and investigated the equilibrium of the resulting system and its characteristics (e.g., influences of system characteristics on the transition phase length). Hong et al. [12] evaluated the impact on emissions of five policies in South Korea. Zis and Psarafis [13] presented a modal split model that estimates modal shifts vis-a-vis competing maritime and land-based modes. Meers et al. [14] developed a choice-based conjoint experiment to increase the insight on the preferences of modal choice decision-makers in Belgium. Dong et al. [15] investigated a modal split transport model of two modes that integrates inventory controls to minimise the long-term expected total costs of transport, inventory holding, and backlogging. Wu et al. [6] applied the modal split model to analyse the attractiveness of different means of transportation in the trade transportation system between China and the Koreas.

As demonstrated in our literature review, there is an increasing interest in the literature in the split model, but to the best of our knowledge, there are no available works that applied a consignment-type multinomial logit model that comprises the cost, time, and $\mathrm{CO}_{2}$ emissions. This is the gap we want to fill: the aim of the paper is to model transport mode choice to replicate the behaviour of decision-makers and to compare it with the minimisation of $\mathrm{CO}_{2} \mathrm{emissions}$ that is, an analysis of the modal shift strategy between rail, road and sea with the MNL model. The other main contribution of the paper is to create, with the retrieved data similar to Hoover's cost and time diagrams [16], a model, " $\mathrm{CO}_{2} \mathrm{Choices}^{\circ}$, that makes it possible to choose the best transportation mode under the objective of $\mathrm{CO}_{2}$ minimisation. The following graphs could be an important tool that can be used by practitioners to quickly identify the least polluting transport modes as a function of the linear distance between the origin and destination.

\section{Methodology}

\subsection{Multinomial Logit Model}

As already stated, the MNL model is one of the most important discrete models used in travel mode choice problems thanks to its simplicity and flexibility [17], and it supposes that the choice of the individual is based on his characteristics and the attributes options while exploiting utility theory [7]. The model is based on the hypothesis that each user $\mathrm{q}$ ( $\mathrm{q}=$ $1 \ldots \mathrm{n})$ assigns to each alternative $\mathrm{i}(\mathrm{i}=1 \ldots \mathrm{m})$ from his set of choices $I q$ a certain utility and chooses the one with the highest utility value:

$$
U_{M}=\max _{i}\left\{U_{i}\right\}
$$

Nevertheless, the decision-maker does not know all the factors that influence the final decision, so the utility is composed of both a systematic $\left(V_{i}^{q}\right)$ and a random part $\left(\varepsilon_{i}^{q}\right)$ :

$$
U_{i}^{4}=V_{i}^{4}+\varepsilon_{i}^{4}
$$

The systematic utility $V_{i}^{q}$ is a linear-in-parameters function that considers a series of determinants $X_{i}^{q}$ (such as cost, travel time...) that affect the final rational choice based on the weights attributed to them by the decision maker $\left(\beta_{k}\right)$ :

$$
V_{i}=\sum_{k} \beta_{k} X_{k i}^{4}
$$

The error term $\varepsilon_{i}^{q}$ represents the deviation from the average value of perceived utility caused by details that cannot be observed. The assumption about the distribution of the error term determines the model [18]: if the random component $\varepsilon_{i}^{q}$ is identically and independently distributed (IID) according to the Weibull-Gumbel distribution, the discrete model is converted into a MNL model [7]. 
The IID principle involves two implications: the mean of the unpredicted terms $\varepsilon_{i}$ is equal to zero, and the independence of irrelevant alternatives (IIA). The model with IID has a choice probability that depends on the utility function of each transport mode and is given by:

$$
p[i]=\frac{e^{V_{i} / \theta}}{\sum_{i} e^{V_{J} / \theta}}
$$

Accordingly, the probability of simulating the correct choices of all decision makers is measured by multiplying each probability $p^{q}$ with the binary variable $i(q)$, which is equal to 1 when the alternative $i$ is chosen by $q$ and zero otherwise.

$$
\prod_{a=1}^{n} p^{q}[i(q)]\left(X^{q}, \beta_{k}, \theta\right)
$$

Exploiting the logarithms' properties and the IIA condition, the same result is obtained with the Maximum LogLikelihood equation $(\log L)$ :

$$
\log L\left(\beta_{k}, \theta\right)=\sum_{a}^{n} \log p^{q}[i(q)]\left(X^{q}, \beta_{k}, \theta\right)
$$

To maximise the probability, so the function (6), the vector of parameters $\beta_{k} / q$ has to be optimised by non-linear programming algorithms. Discrete mode choice models use various types of factors: generic variables are applied in the utility of all the alternatives, whereas specific attributes are evaluated in different way for each alternative. These kinds of attributes are called "Alternative-Specific Attributes" (ASA) and behave as binary variables and consider some qualitative features that cannot be quantified (such as the comfort of the mode of transport). To quantify all these factors, data can be collected through a Stated-Preference (SP) or a Revealed-Preference (RP) survey: the first technique consists in analysing some different scenarios, the second one collects real data on the effective behaviour of users.

In these types of applications, variables are fixed also for all decision-makers: this means that preferences are homogeneous across individuals. To solve this restriction, the use of a Mixed Logit (ML) model is preferred to MNL. To get a correct application of the MNL model, it is necessary to assign transports to third-party providers (3PL) and respect the IIA condition.

The rho-square value represents the level of accuracy of the model; it varies from zero to one (maximum accuracy) and it is measured as follows:

$$
\rho^{2}=1-\frac{\log L\left(\beta^{*}\right)}{\log L(0)}
$$

where $\log L\left(\beta^{*}\right)$ is the optimised $\log$-Likelihood $(\log L)$ equation (with the vector of optimised parameters $\beta_{k}^{*} / \theta$ ), and $\log L(0)$ is the Log-Likelihood equation with coefficients $\beta_{k}$ set equal to zero, which has, by definition, no significance.

\subsection{Hoover's diagram and extension}

The objective of this paper is not only to use the MNL model to analyse the benefits obtained by the application of a modal shift strategy in a specific case study, but also to give some innovative indications to transportation research. The state of the art of transport modal choice does not provide any guidelines regarding transport modal assignment based on carbon emissions. It is important to introduce some new considerations about the topic of green transport modal choice in industry's transportation in light of the EU policy. Hoover defined diagrams regarding transport mode choice based on cost and time factors [16]. One of these is particularly useful because it shows in an approximate way the break-even points between the cost of transport by road, rail, air and sea when varying the distance (Figure 1 left). It also shows that the optimisation of the overall cost for long distances derives from the sequential combination of truck, rail, and ship modes. Sea transport dominates the transport of goods over medium and long distances [19], whereas land transport prevails over medium-short distances due to its flexibility and capillarity [20]. Another Hoover diagram in Figure 1 right compares various types of transport (rail, road and air) based on the transit time and distance.
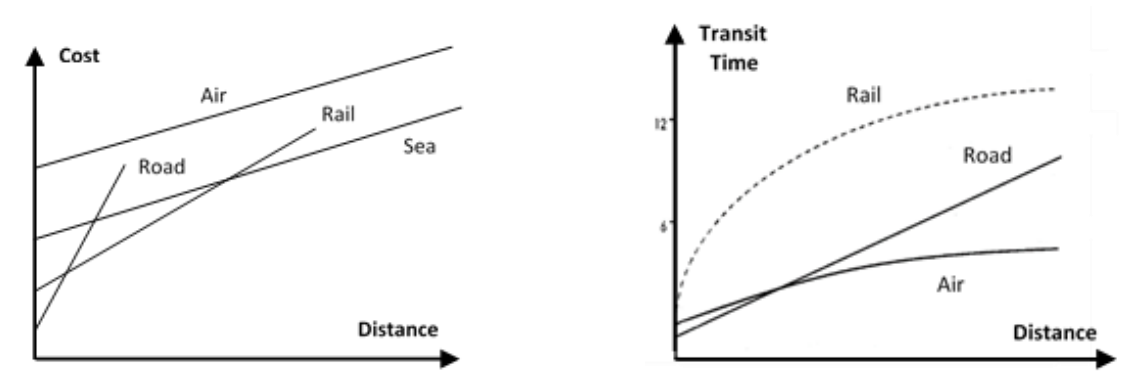

Fig. 1. Hoover's cost and distance diagram (left) and time and distance diagram (right) 
Tot.Emissions $\left[\mathrm{gCO}_{2}\right]=$ Weight $[$ tonne $] \times$

Effective distance $[\mathrm{km}]$ Carbon emission factor $\left[\mathrm{gCO}_{2} /\right.$ tonnekm $]$

To reach this goal, all transport modes are compared according to their environmental impact per kilometre. The total amount of emissions is calculated through Eq. (8). For the carbon emission factors, the reader can refer to those listed in Table 1, which are the ones used in our case study. In these calculations, weights represent a useless variable because they are identical for each transport alternative and directly proportional to $\mathrm{CO}_{2}$ emissions, so they are assumed for simplicity as equal to one tonne. Our extension of the Hoover diagram is reported in the case study section, since it relies on the data presented there.

\section{Model development and results discussion}

The implementation of these kinds of models can be articulated through three basic steps:

- Specification: definition of the parameters, set of alternatives, and initial hypotheses.

- Calibration: optimisation of the coefficients $\left(\beta_{k}, \theta\right)$ to maximise the likelihood.

- Validation: verification of the goodness of the model's outputs.

The data included in the application refer to the transport schedules of one of the most important companies operating in the chemical sector in Europe, which has headquarters near Padova, Italy. Italian customers represent the leading destinations by sales volume and turnover: the database comprises almost all the national transport shipments made in 2018. In reality, the company assigns all its transport to third-party providers (3PL), but tankers, intercompany and multidelivery shipments and express deliveries are excluded from the database for simplicity. The final sample totals 1361 despatches, divided between 282 Italian customers. The data have been collected through an RP survey since the model is based on despatches that have already happened. In addition to road transport, the only mode used by the company for this transport, the model will consider rail, sea and air modes. To calculate every single route of each mode, some Italian logistics terminals have been identified: Italy's 30 leading railway centres, 30 ports and 30 airports are introduced into the database. Since Padova is the location of departure, the port and the airport of Venice and the terminal of Padova represent the nearest logistic points for ocean, air and railway modes, respectively. According to the mode chosen, which is indicated by the binary variable $i(q)$, the model will calculate the correct weight $\left(\beta_{k} / \theta\right)$ to assign to the determinants $X_{i}^{q}$ to simulate the real mode choice at best. In the following case study, the freight service attributes that will influence the choice are cost, transit time, $\mathrm{CO}_{2}$ emissions and availability (which defines if an alternative is available or not).

For the development, it was necessary to collect a lot of information: the value of each attribute for each option and destination. In doing this, some approximations have been made. The costs and transit times of the road transport consignments have been obtained from the rates of real carriers. Toll rates are expressed in terms of $€ / \mathrm{km}$ and the rates are applied for weight ranges: $2500<\mathrm{kg}<7500 ; 7500<\mathrm{kg}<15000$ and $15000<\mathrm{kg}<30000$. For rail and maritime modes, some quotations were collected: the information concerns both groupage and full container loads (20' and 40'). The data collected include the cost and time of the road transport necessary for the initial and final routes. Cost and transit time were generalised with Excel through trend lines as functions of the distance travelled to quantify every attribute for each destination. Although the price lists of the two leading companies in the sector were considered for air consignments, this alternative is not very useful due to the huge weights shipped and short distances that characterise the national territory. Moreover, their $\mathrm{CO}_{2}$ emissions are very high, and run counter to the minimisation of the environmental impact. A parameter was introduced for availability: it is a binary variable that assumes a value equal to one if the alternative cannot be used, zero otherwise. Hence, the air mode is always set as unavailable a priori, while the availability of other types of transport depends on the province of destination. Obviously, the road mode, thanks to its flexibility and extensive coverage, always represents a feasible solution. The objective of the application concerns the minimisation of $\mathrm{CO}_{2}$ emissions, and with this aim a parameter is introduced into the model: each type of transport emits a specific amount of $\mathrm{CO}_{2}$ emissions and there are several methods in the literature to quantify these values. Here the quantification is based on the Activity-Based approach [21]. In Table 1 the recommended carbon emission factors that will be used in the subsequent application are shown. These coefficients are taken directly from [22].

\begin{tabular}{|c|c|}
\hline Transport mode & $\mathbf{g C O}_{\mathbf{2}}$ / tonne km \\
\hline Road & 62 \\
\hline Rail & 22 \\
\hline Sea & 8 \\
\hline Air & 602 \\
\hline
\end{tabular}

Table 1. Recommended emission factors

\subsection{Relation between linear and real distance}

The calculation of real distances represents crucial and indispensable information for all types of transport and attributes. The huge potential of Google Maps Platform has been exploited using the Google Maps Distance Matrix 
Application Programming Interface (API) [23] on Excel to compute almost all the road routes and some rail distances. Nevertheless, this technique cannot be exploited for sea and air. Thus, each address was converted into geographic coordinates (latitude and longitude) and the linear distance was measured with the Google Maps Geocoding API. The linear distance between two locations (A,B with latitudes and longitudes defined as $a_{i}$ and $b_{i}$, respectively) is calculated with Equation (9), where 6.378 is the length of the radius of the Earth using the Spherical Law of Cosines [24].

$$
d(A, B)=\cos ^{-1}\left(\cos \left(a_{1}-a_{2}\right) \times \cos \left(b_{1}\right) \times \cos \left(b_{2}\right)+\sin \left(b_{1}\right) \times \sin \left(b_{2}\right)\right) * 6.378
$$

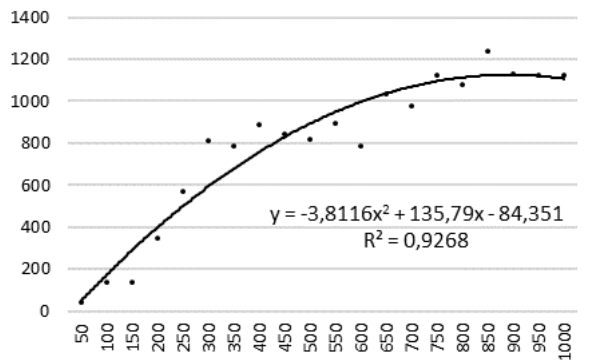

Fig. 2. Best trend between linear and real distances for sea mode

Linear distances between airports were assumed as the routes of the air transport mode. For the unavailable sea routes, we compared some real maritime routes with linear routes to get trend lines to predict sea routes as a function of the linear distances between ports. More than 400 real sea routes were collected in the initial sample, which is significant [25], and the linear distances were categorised into some numbered sections. Then the best trend (exponential, linear, logarithmic, polynomial or potential trend), with the best $\mathrm{R}^{2}$, was chosen. Figure 2 shows the result for sea transports: the $\mathrm{X}$-axis contains the linear distance categories (in this case, they were divided into classes of $50 \mathrm{~km}$ ) and the Y-axis reports the averages of the real distances for each category. The same technique is extended also to the other alternatives and samples of almost 500 routes were gathered using Google Maps and categories of $25 \mathrm{~km}$ were set (Figure 3).
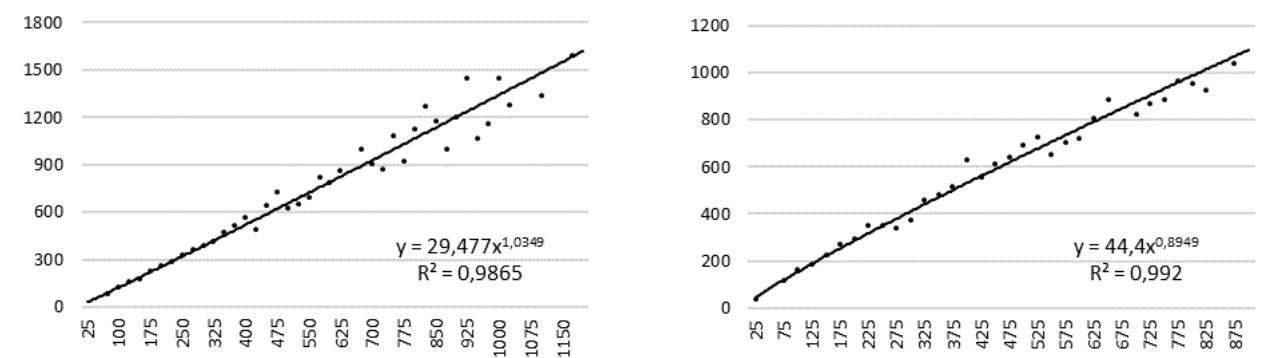

Fig. 3. Best trend between linear and real distances for road mode (left) and rail mode (right)

Table 2 reports for each transport mode the dimension of the categories, the best trend line and the corresponding correlation coefficient $\left(\mathrm{R}^{2}\right)$. Thus, the trend line makes it possible to simulate real distances y starting from the linear distance classes, because $\mathrm{x}$ represents the number of each category. For example, in the first category of $50 \mathrm{~km} \mathrm{x}$ is equal to one, in the second category $(100 \mathrm{~km}) \mathrm{x}$ is equal to two and so on. Despite the approximation, $\mathrm{R}^{2}$ shows very high values that make the use of these distances very reliable in $\mathrm{CO}_{2}$ calculation.

\begin{tabular}{|c|c|c|c|}
\hline Transport mode & Class dimensions & Best trend line & Correlation coefficient $\left(\mathbf{R}^{2}\right)$ \\
\hline Road & $25 \mathrm{~km}$ & $\mathrm{y}=29.477 \mathrm{x}^{1.03}$ & $\mathrm{R}^{2}=0.98$ \\
\hline Rail & $25 \mathrm{~km}$ & $\mathrm{y}=44.4 \mathrm{x}^{0.89}$ & $\mathrm{R}^{2}=0.99$ \\
\hline Sea & $50 \mathrm{~km}$ & $\mathrm{y}=-3.81 \mathrm{x}^{2}+135.79 \mathrm{x}-84.35$ & $\mathrm{R}^{2}=0.97$ \\
\hline
\end{tabular}

Table 2. Best trends for national transport modes

Hence, every distance between two transhipment centres or two ports will be approximated starting from the linear distance, and the connections with the origin and the destination will be rightly measured as road routes and multiplied by the specific carbon emission factor $\left(62 \mathrm{gCO}_{2} / \mathrm{tkm}\right)$.

\subsection{Results}

As a first goal, the MNL model to simulate the company's decision about the model transport mode choice has been applied. The MNL assigns an optimised weight to the model's attributes in order to replicate the decision-maker's choices. Alternatives included in the model are road, rail, sea and air, whereas attributes are cost [€], transit time availability [days] 
and $\mathrm{CO}_{2}$ emissions $\left[\mathrm{kgCO}_{2} /\right.$ tonnekm]. In 2018 the only means of transport used by the analysed company was trucks, so the model will have to assess this choice in all of the 1361 instances. Table 3 shows the most interesting values to analyse: $\beta_{k} / q$ coefficients of each attribute, $\operatorname{LogL}(0), \operatorname{LogL}\left(\beta^{*}\right)$, the value of the $\rho^{2}$ test (which is the best indicator of the effectiveness of MNL models) and the number of errors committed by the specific application. Although the values of the attributes' coefficients depend on the unit of measures with which the parameters are quantified, the results reveal that the availability correctly represents the first determinant of choice, whereas time and cost are used secondly by the model to distinguish the alternatives. Emissions are not much considered, so the sign of its coefficient is wrongly positive: this means that the model does not replicate correctly the real choices. Although the value of the $\rho^{2}$ test is almost perfect, the model chooses the wrong alternative 11 times $(0.8 \%)$. To reduce errors, the air mode is eliminated from all the calculations and the results are shown in Table 3. In this last case, all the signs are correct, there are no errors in the simulation, and the result of the test is even better than before. This means that the model works perfectly without considering the air mode, which is a useless alternative also in real national transport consignments.

In order to minimise $\mathrm{CO}_{2}$ emissions, it is necessary to set a priori $i(q)=1$ in correspondence with the most environmentally friendly alternative so that the approach returns for each shipment the choice probability of each mode if the company in 2018 had decided to minimise the carbon dioxide emissions of its national transport schedule. This application represents a novelty compared to the state of the art because nobody has ever used the MNL model with this particular objective. Emissions' calculation refers to Equation (8) and depends on the recommended carbon emission factors $\left(\mathrm{kgCO}_{2} /\right.$ tonnekm), transport weights and effective distances travelled. Table 4 shows the results derived from $\mathrm{CO}_{2}$ optimisation: it is evident that the exclusion of the air mode led to better values also in this case. All the coefficients show signs and values that fit with the initial hypothesis: the model recognises availability as the most important attribute, then the choice probability depends on the emissions factor, as expected; cost and time have a rather low incidence on the selection and all the negative signs show that the MNL model works correctly. However, the $\rho^{2}$ test assumes a worse, but almost acceptable, value ( 0.95). The instances that present a wrong choice are only three, and they are caused by the very small difference in carbon production: in fact, trucks prevail over the railway even though the latter emits less $\mathrm{kgCO}_{2}$ than the former. The ratio of $\beta$ coefficients represents another good indicator of the model's accuracy: if we divide $\beta_{\text {emiss }}$ and $\beta_{\text {cost }}$ we will get a sort of "Value of Emissions" (VoE) that indicates the importance given to the emissions factor. Excluding the air mode from the calculation, the $\mathrm{VoE}$ grows from $1079 € / \mathrm{kgCO}_{2}$ to $1530 € / \mathrm{kgCO}_{2}$ and this means that the carbon emissions assume a greater importance in the last application. These values are distantly comparable with those of the first simulation, where the $\mathrm{VoE}$ (without air mode) is equal to $1.84 € / \mathrm{kgCO}_{2}$.

\begin{tabular}{|c|c|c|c|}
\hline \multicolumn{2}{|c|}{ With air mode } & \multicolumn{2}{|c|}{ Without air mode } \\
\hline Values of $\boldsymbol{\beta}$ & Values of accuracy & Values of $\boldsymbol{\beta}$ & Values of accuracy \\
\hline$\beta_{\text {cost }}=-0.52$ & $\log L(0)=-819.40$ & $\beta_{\text {cost }}=-0.0057$ & $\log L(0)=-649.36$ \\
\hline$\beta_{\text {time }}=-52.16$ & $\log L\left(\beta^{*}\right)=-4.83$ & $\beta_{\text {time }}=-23.97$ & $\log L\left(\beta^{*}\right)=-0.0034$ \\
\hline$\beta_{\text {avail }}=-279.27$ & $\rho^{2}=0.99$ & $\beta_{\text {avail }}=-101.91$ & $\rho^{2}=0.99$ \\
\hline$\beta_{\text {emiss }}=+0.73$ & $\mathrm{~N}^{\circ}$ errors $=6(0.4 \%)$ & $\beta_{\text {emiss }}=-0.01$ & $\mathrm{~N}^{\circ}$ errors $=0$ \\
\hline
\end{tabular}

Table 3. Company's choices with and without air mode

\begin{tabular}{|c|c|c|c|}
\hline \multicolumn{2}{|c|}{ With air mode } & \multicolumn{2}{|c|}{ Without air mode } \\
\hline Values of $\beta$ & Values of accuracy & Values of $\beta$ & Values of accuracy \\
\hline$\beta_{\text {cost }}=-0.0001$ & $\log L(0)=-819.40$ & $\beta_{\text {cost }}=-0.0003$ & $\log L(0)=-$ \\
\hline$\beta_{\text {time }}=-0.0753$ & $\log L\left(\beta^{*}\right)=-70.72$ & -0.1596 & $\log L\left(\beta^{*}\right)=-33.26$ \\
\hline$\beta_{\text {avail }}=-110.23$ & $\rho^{2}=0.91$ & $\beta_{\text {avail }}=-135.6015$ & $\rho^{2}=0.95$ \\
\hline$\beta_{\text {emiss }}=-0.1897$ & $\mathrm{~N}^{\circ}$ errors $=11(0.8 \%)$ & $\beta_{\text {emiss }}=-0.5699$ & $\mathrm{~N}^{\circ}$ errors $=3(0.2 \%)$ \\
\hline
\end{tabular}

Table 4. $\mathrm{CO}_{2}$ minimisation with and without air mode

The model is able to express both cases with great significance. The information that can be extrapolated from this latter numerical case is numerous and very interesting because we can analyse the effects of a shift in modal strategy. In 2018 the company chose only road transport, and the model makes it possible to study the consequences that a different choice would have entailed. Excluding the three errors committed by the model, the $\mathrm{CO}_{2}$ minimisation led to the following optimisations:

- $62.5 \%$ of transport consignments should be transferred from road to a different mode, or rather:

- 642 deliveries $(47.3 \%$ ) should be transferred to rail;

○ 206 deliveries $(15.2 \%)$ should be made by sea mode.

- The emissions saved in a year would be at most 138.74 tonCO $\mathrm{CO}_{2}$, which means an overall reduction of $41 \%$ (if all the national transport consignments of 2016 took place on the road, as really happened, the impact would be 336.11 ton $\mathrm{CO}_{2}$ ), in particular:
○ 60.88 tonCO $\mathrm{CO}_{2}(43,9 \%)$ thanks to the railway;
○ 77.86 tonCO $\mathrm{CO}_{2}(56,1 \%)$ thanks to the sea transport; 
- On average, the saving for each of the 1358 transport consignments would be equal to $102 \mathrm{kgCO}_{2}$, made up of:

○ $95 \mathrm{kgCO}_{2}$ for each of the 642 rail deliveries;

○ $378 \mathrm{kgCO}_{2}$ for each of the 206 sea deliveries.

The MNL model confirms that the least polluting modes, from which the highest emission savings are obtained, are rail and sea mode. Nevertheless, these alternative solutions lead to an increase in the transit time and cost of transport: in order to minimise carbon emissions, an increase in transit time of more than one day for each shipment and an increase of the costs equal to $50 \%$ (principally caused by the transfer to sea mode) are necessary.

In the following graphs, the $\mathrm{x}$-axis considers the linear distance $[\mathrm{km}]$ between two generic points, whereas the y-axis reports the total amount of carbon emissions $\left[\mathrm{kgCO}_{2} /\right.$ tonne]. The assessment was conducted with respect to the Italian territory, divided into 3 main areas: northern, central and southern Italy. Table 5 indicates that the average distances assume different values for northern, central and southern Italy, in particular for sea and rail modes (obviously, road does not provide any change of transport mode). It is derived that the higher the total road distance is, the greater the initial carbon footprint and, consequently, the value of the intercept with the y-axis. So, the $\mathrm{CO}_{2}$ emissions caused by each mode are measured according to Equation (8) and the best approximation lines are chosen in order to maximise the correlation coefficient $\left(\mathrm{R}^{2}\right)$. Figure 4 shows the emissions-distance diagram for northern, central and southern Italy. Indeed, it is possible to outline some general principles that can help the user to choose the type of transport and apply a modal shift strategy: in northern Italy, as in the Hoover cost diagram, the optimal sequence is defined by the succession of road, rail and sea modes. Air mode can be excluded from this study due to its high pollution. In general, we can say that for short distance routes it is advisable to use road vehicles, while for long distances sea transports. Furthermore, the emissions balancing points between rail-road and rail-sea are located around $150 \mathrm{~km}$ and $450 \mathrm{~km}$, respectively. For central and southern Italy, the situation is slightly different due to the presence of a single point of balance between truck and sea, which stands around $150 \mathrm{~km}$. In fact, the lower distances of ports and higher distances with rail terminals give the sea mode an advantage such that it assumes a predominant role in the modal shift strategy. It is important to understand that these results depend strictly on the morphology and the specific infrastructure network of the territory: this analysis could be considered valid only within the Italian borders.

\begin{tabular}{|c|c|c|}
\hline Zone & Air & Sea \\
\hline Northern Italy & 100 & 200 \\
\hline Central Italy & 125 & 135 \\
\hline Southern Italy & 100 & 135 \\
\hline Northern Italy & 100 & 200 \\
\hline
\end{tabular}

Table 5. Average distances for air, sea and rail modes

These considerations are not necessarily always true, and it would be interesting to compare them with a specific case or rather the MNL application. In the previous study, the model allowed us to assign to each destination the least polluting alternative, so it is possible to gather all the distances in different ranges and match the results with the emission-distance diagram of northern Italy, considering that the company is located in Padova (Veneto region). In Table 6 all 1358 transport consignments are categorised according to the road distance travelled (which differs slightly from linear distances but is still quite comparable) in eleven categories. Hence, for each zone the predominant alternative is selected according to the sum of all choices. We can see that the final results reflect the general guidelines quite well because the balancing points are very similar to those in the emissions-distance charts: we see that the values of these points are more or less $150 \mathrm{~km}$ and $450 \mathrm{~km}$.
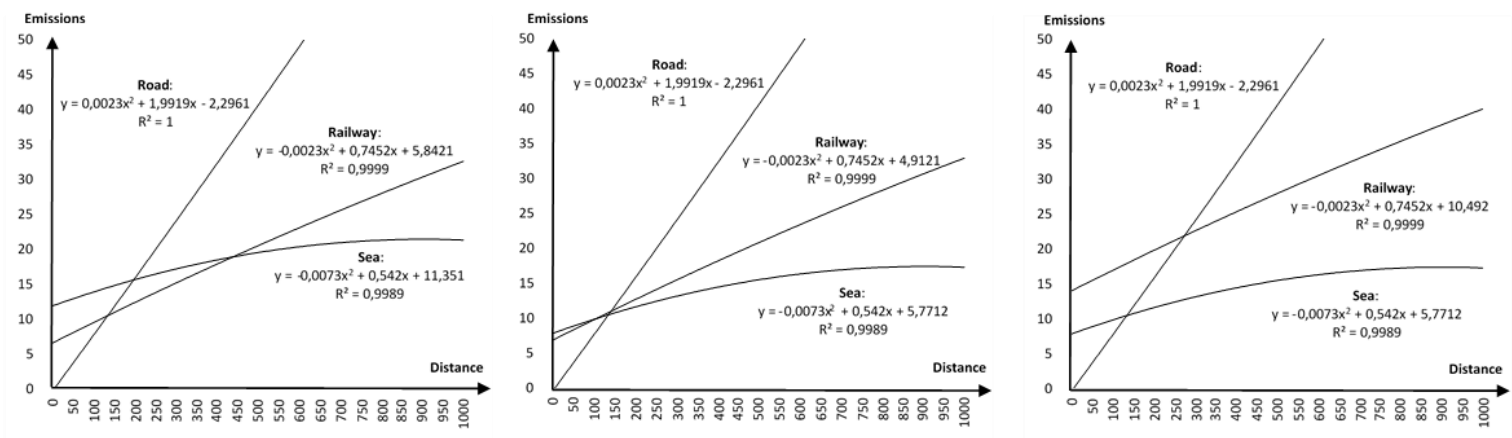

Fig. 4. Emissions-distance diagram for northern (left), central (centre) and southern (right) Italy origins

In this study the transition from road to rail is attested at around 100/200 km and the sea prevails over the railway in the $400<=\mathrm{km}<500$ category. However, between 200 and $300 \mathrm{~km}$ the gap between truck and rail assignments is almost null and there is a sort of equivalence. Despite this, it is evident that the element of greatest incongruity is represented by the choice of destinations that are about $600 / 700 \mathrm{~km}$ : the diagram indicates sea transport as the best alternative, while the 
MNL model finds that rail is best. This incongruence could be caused by the Italian morphology: at this distance lie destinations in the Lazio region and the choice of sea would imply the circumnavigation of the whole eastern and southern part of the peninsula, which means an excessively long path compared to the direct link offered by the Italian railway network. Indeed, we can prove this affirmation by analysing the partition of modal choice according to each Italian region (Table 7 and Figure 5): the best solution for transport to the Lazio region is definitely the railway due to its choice probability of $98 \%$ (51 times out of 52 shipments). Although the Marche and Umbria regions are closer to the origin, it is better to use the sea mode in order to minimise $\mathrm{CO}_{2}$ emissions thanks to the opportunity of landing in the port of Ancona.

\begin{tabular}{|c|c|c|c|c|c|}
\hline Distance & Total & Road & Rail & Sea & Best \\
\hline$<50 \mathrm{~km}$ & 167 & 167 & - & - & Road \\
\hline $50<=\mathrm{km}<100$ & 74 & 62 & 12 & - & Road \\
\hline $100<=\mathrm{km}<200$ & 349 & 119 & 228 & 2 & Rail \\
\hline $200<=\mathrm{km}<300$ & 348 & 162 & 164 & 22 & Rail \\
\hline $300<=\mathrm{km}<400$ & 188 & - & 146 & 42 & Rail \\
\hline $400<=\mathrm{km}<500$ & 19 & - & 3 & 16 & Sea \\
\hline $500<=\mathrm{km}<600$ & 62 & - & 28 & 34 & Sea \\
\hline $600<=\mathrm{km}<700$ & 51 & - & 44 & 7 & Rail \\
\hline $700<=\mathrm{km}<800$ & 96 & - & 17 & 79 & Sea \\
\hline $800<=\mathrm{km}<900$ & 3 & - & - & 3 & Sea \\
\hline$>1000 \mathrm{~km}$ & 1 & - & - & 1 & Sea \\
\hline Total & $\mathbf{1 3 5 8}$ & $\mathbf{5 1 0}$ & $\mathbf{6 4 2}$ & $\mathbf{2 0 6}$ & \\
\hline
\end{tabular}

Table 6. The partition of modal choice in the case study based on effective road distance

\begin{tabular}{|c|c|c|c|c|c|}
\hline Italian Region & Total & Road & Rail & Sea & Best \\
\hline Veneto & 256 & 242 & 14 & - & Road \\
\hline Friuli Venezia Giulia & 29 & - & 25 & 4 & Rail \\
\hline Trentino Alto Adige & 22 & - & 22 & - & Rail \\
\hline Lombardia & 485 & 234 & 251 & - & Rail \\
\hline Emilia Romagna & 93 & 34 & 39 & 20 & Rail \\
\hline Piemonte & 145 & - & 145 & - & Rail \\
\hline Toscana & 66 & - & 57 & 9 & Rail \\
\hline Lazio & 52 & - & 51 & 1 & Rail \\
\hline Marche & 39 & - & - & 39 & Sea \\
\hline Umbria & 10 & - & - & 10 & Sea \\
\hline Abruzzo & 54 & - & 21 & 33 & Sea \\
\hline Molise & 2 & - & - & 2 & Sea \\
\hline Campania & 99 & - & 17 & 82 & Sea \\
\hline Basilicata & 5 & - & - & 5 & Sea \\
\hline Calabria & 1 & - & - & 1 & Sea \\
\hline Total & $\mathbf{1 3 5 8}$ & $\mathbf{5 1 0}$ & $\mathbf{6 4 2}$ & $\mathbf{2 0 6}$ & \\
\hline
\end{tabular}

Table 7. The partition of modal choice in the case study based on Italian regions

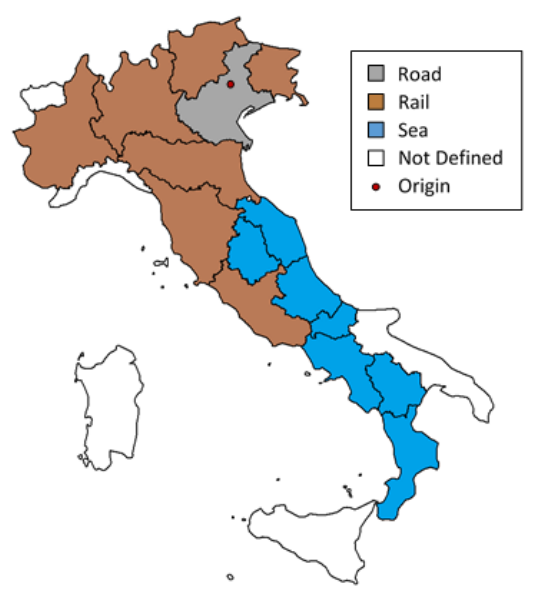

Fig. 5. The map of the partition of modal choice in the case study based on Italian regions 
The most important emissions reductions derive from the shift to sea mode for shipments in Campania $(41.5 \%$, or rather 57.56 ton $\mathrm{CO}_{2}$ ) and to the use of rail mode for shipments directed to Lazio and Piemonte (17\% and $16 \%$ reduction, respectively), whereas the shift from road to rail in the Veneto region for 14 shipments leads "only" to a reduction of $0.04 \%$ (5.5 tonCO $\mathrm{C}_{2}$ ). Except for Veneto, Lombardia and Emilia Romagna, which continue to need some shipments by truck, the other regions shift all their transport to more sustainable alternatives. Finally, other interesting information that can be obtained from this application is that the emissions caused by shipments at the current state could already be optimised by a modal shift strategy with the same costs: the result would be a reduction of 82.8 tonCO $\mathrm{O}_{2}$, so $60 \%$ of the maximum possible optimisation $\left(138.74\right.$ tonCO $\left.\mathrm{C}_{2}\right)$ and $24.6 \%$ of what it would be if all the goods travelled by road (336.11 ton $\mathrm{CO}_{2}$ ). The total emission reduction corresponds to $510(37.5 \%)$ deliveries by truck, $642(47.3 \%)$ and $206(15.2 \%)$ deliveries by rail and sea, respectively. However, at the same costs it could be possible to have a reduction of $24.6 \%$ : in this case, the partition of road, rail and sea would become roughly $72 \%, 22 \%$ and $6 \%$, respectively.

\section{Conclusion}

This paper offers a better understanding of freight transport modal choice and new contributions to the literature through the application of the MNL model in transport modal choice under the objective of $\mathrm{CO}_{2}$ emission minimisation and the definition of new guidelines in order to identify the most sustainable transport solution as a function of distance along the same lines as Hoover's diagrams. The case study refers to part of the national outbound transport consignments of a company based near Padova (Italy), in 2018. The results obtained make it possible to highlight some significant aspects that can support the planning of shipments of goods and the choice of the mode of transport in relation to parameters that are already usually considered (particularly costs and distances), but also considering the aspect of environmental sustainability as a decision-making factor (represented specifically by $\mathrm{CO}_{2}$ emissions).

The application of the MNL model shows a satisfactory overall fit $\left(\rho^{2} \sim 0.95\right)$. Except for three wrong instances $(0.2 \%)$, the model manages to simulate the application of a modal shift strategy and the change to more sustainable transport modes. The information that could be extracted is very interesting; for example $62.5 \%$ of shipments should be transferred from truck to a different mode and the total emissions saved in a year would be at most 138.74 tonCO $\mathrm{O}_{2}$, or rather a reduction of $41 \%$. The same results allow us to make a different and detailed analysis, and in fact it was possible to show another important contribution to the literature, along the same lines as Hoover's diagrams, which identify the cheapest and the fastest transport modes according to the distance travelled. In other words, Hoover offers some guidelines based on distances in order to choose the best transport mode that minimises the cost and the transit time, whereas this paper introduces some new general principles that can help users to choose the transport mode that minimises $\mathrm{CO}_{2}$ emissions according to the linear distance between any origin and destination within Italy. In particular, for locations in northern Italy, the emissions balancing points between rail-road and rail-sea are located around $150 \mathrm{~km}$ and $450 \mathrm{~km}$, respectively. Despite this, some questions remain outstanding, and there are some points that need to be further explored. A lot of the initial data are obtained from approximations: the model's attributes assume values that are collected through requests for quotations that have been generalised to complete the data set. In fact, for each transport mode (road, rail, sea, air) it is necessary to measure the value of each variable (cost, time, $\mathrm{CO}_{2}$ emissions, availability): from the number of instances equal to 1361 consignments, it is evident that the amount of data needed is quite substantial. For simplicity, the weight categories that are considered in the model are $2500<\mathrm{kg}<7500,7500<\mathrm{kg}<15000$, and $15000<\mathrm{kg}<30000$ and all road shipments are assumed as to be directly transported by lorry from the origin to the customer. Also, the costs and transit times should be measured specifically for each case and not approximated by trend lines.

\section{References}

[1] International Energy Agency (2017). World Energy Outlook 2017 (2017). ISBN: 9789264282308. https://doi.org/10.1787/WEO-2017-EN.

[2] Farahani, R.; Rezapour, S.; Kardar, L. (2011). Logistics Operations and Management, Elsevier 2011, ISBN: 9780323165204. https://doi.org/10.1016/C2010-0-67008-8.

[3] Steadieseifi, M.; Dellaert, N.P.; Nuijten, W.; Van Woensel, T.; Raoufi, R. (2014). Multimodal freight transportation planning: A literature review. Eur. J. Oper. Res., 233, 1-15. https://doi.org/10.1016/j.ejor.2013.06.055.

[4] de M. Pinto, J.T.; Mistage, O.; Bilotta, P.; Helmers, E. (2018). Road-rail intermodal freight transport as a strategy for climate change mitigation. Environ. Dev., 25, 100-110. https://doi.org/10.1016/j.envdev.2017.07.005.

[5] Flodén, L.; Bärthel, F.; Sorkina, E. (2017). Transport buyers choice of transport service - A literature review of empirical results. Res. Transp. Bus. Manag., 23, 35-45. https://doi.org/10.1016/j.rtbm.2017.02.001.

[6] Wu, S.; Sun, Y.; Yang, Z. (2020). Analyzing the trade transportation and its demand on multimodal transportation system between China and Koreas. Marit. Bus. Rev., 5, 84-98. https://doi.org/10.1108/MABR-08-2019-0033.

[7] McFadden, D. (1981) Econometric Models of Probabilistic Choice. In: Manski, C. and McFadden, D., Eds., Structural Analysis of Discrete Data with Econometric Applications, MIT Press, Cambridge, 198-272.

[8] Ben-Akiva, M.; Bierlaire, M. (1999). Discrete Choice Methods and their Applications to Short Term Travel Decisions. Handbook of Transportation Science, Kluwer, 5-33. https://doi.org/10.1007/978-1-4615-5203-1_2.

[9] Dalla Chiara, B.; Deflorio, F.P.; Spione, D. (2008). The rolling road between the Italian and French Alps: modeling the modal split. Transp. Res. Part E Logist. Transp. Rev., 44, 1162-1174. 
[10] Sivakumar, A.; Bhat, C. (2002). Fractional Split-Distribution Model for Statewide Commodity-Flow Analysis. Transportation Research Record: Journal of the Transportation Research Board, 1790, 1, 80-88. https://doi.org/10.3141/1790-10.

[11] Ferrari, P. (2014). The dynamics of modal split for freight transport. Transp. Res. Part E Logist. Transp. Rev., 70, 163-176. https://doi.org/10.1016/J.TRE.2014.07.003.

[12] Hong, S.; Chung, Y.; Kim, J.; Chun, D. (2016). Analysis on the level of contribution to the national greenhouse gas reduction target in Korean transportation sector using LEAP model. Renew. Sustain. Energy Rev., 60, 549-559. https://doi.org/10.1016/J.RSER.2015.12.164.

[13] Zis, T.; Psaraftis, H.N. (2017). The implications of the new sulphur limits on the European Ro-Ro sector. Transp. Res. Part D Transp. Environ., 52, 185-201. https://doi.org/10.1016/J.TRD.2017.03.010.

[14] Meers, D.; Macharis, C.; Vermeiren, T.; van Lier, T. (2017). Modal choice preferences in short-distance hinterland container transport. Res. Transp. Bus. Manag., 23, 46-53. https://doi.org/10.1016/j.rtbm.2017.02.011.

[15] Dong, C.; Transchel, S.; Hoberg, K. (2018). An inventory control model for modal split transport: A tailored basesurge approach. Eur. J. Oper. Res., 264, 89-105. https://doi.org/10.1016/j.ejor.2017.05.010.

[16] Florence, P.S.; Hoover, E.M. (1949). The Location of Economic Activity. Econ. J., 59, 221. https://doi.org/10.2307/2226687.

[17] Arbués, P.; Baños, J.F.; Mayor, M.; Suárez, P. (2016). Determinants of ground transport modal choice in longdistance trips in Spain. Transp. Res. Part A Policy Pract., 84, 131-143. https://doi.org/10.1016/j.tra.2015.06.010.

[18] Patterson, Z.; Ewing, G.O.; Haider, M. (2010). How different is carrier choice for third party logistics companies?. Transp. Res. Part E Logist. Transp. Rev., 46, 764-774. https://doi.org/10.1016/j.tre.2010.01.005.

[19] Orlic Protega, A.; Rogic, K.; Vrdoljak, J. (2011). Logistic approaches to port management system. Ann. DAAAM Proc. Int. DAAAM Symp., 22, 1053-1054.

[20] Mlinaric, T.J.; Rados, B.; Vajdic, M. (2017). Proposal for the implementation of the european rail traffic management system (ertms) to the railway network in the republic of Croatia. Ann. DAAAM Proc. Int. DAAAM Symp., 109-117. https://doi.org/10.2507/28th.daaam.proceedings.014.

[21] European Commission (2017). COMMISSION REGULATION (EU) 2017/2400 of 12 December 2017 implementing Regulation (EC) No 595/2009 of the European Parliament and of the Council as regards the determination of the $\mathrm{CO} 2$ emissions and fuel consumption of heavy-duty vehicles and amending Directive 2007/46/EC of the European Parliament and of the Council and Commission Regulation (EU) No 582/2011.

[22] Cichosz, M.; Nowicka, K.; Pluta-Zaremba, A.; Moritz, N. (2018). Toolbox element: CO2 calculator deliverable 1.2 .9 version $202 / 2018$.

[23] Google Developers (2021). Distance Matrix API. https://developers.google.com/maps/documentation/distancematrix/overview (accessed July 21, 2021).

[24] Gellert, W. (1989). The VNR concise encyclopedia of mathematics, 776.

[25] Sallauka, A.; Likaj, R. (2019). Performance of Dijkstra, Floyd and Astar Algorithms for Urban Transport Lines. Ann. DAAAM Proc. Int. DAAAM Symp., 21, 265-270. 